\title{
Retraction Note to: Electrophysiological Follow-Up of Patients with Chronic Peripheral Neuropathy Induced by Occupational Intoxication with $\mathrm{n}$-Hexane
}

\section{Cheng Wang ${ }^{1,2,3} \cdot$ Shijiu Chen ${ }^{2} \cdot Z_{\text {Zengtao Wang }}^{1,3}$}

Published online: 28 October 2021

(c) Springer Science+Business Media, LLC, part of Springer Nature 2021

Retraction to: Cell Biochem Biophys (2014) 70:579-585 https://doi.org/10.1007/s12013-014-9959-7 published online 23 May 2014

The Editor-in-Chief has retracted this article at the request of the corresponding author. Concerns were raised regarding the authorship of the article and the source of the data. The first author Cheng Wang admitted to including the corresponding author Zengtao Wang in the paper without their agreement and obtaining the article from a third party. The authors have confirmed that Zengtao Wang was unaware of the study until after publication.

All authors agree to this retraction.
The original article can be found online at https://doi.org/10.1007/ s12013-014-9959-7.

Zengtao Wang

drzengtaowang@163.com

1 Southern Medical University, 510515 Guangzhou, People's Republic of China

2 Department of Hand Surgery, The Fifth Affiliated Hospital of Zunyi Medical College, 519100 Zhuhai, People's Republic of China

3 Department of Hand and Foot Surgery, Provincial Hospital Affiliated to Shandong University, 250021 Jinan, People's Republic of China 